\title{
Acute Aortic Thrombus with Splenic Infarction in a Patient with COVID-19 Infection
}

\author{
Priya Singh \\ Sanjay Gandhi Postgraduate Institute of \\ Medical science, Lucknow, India \\ Corresponding author: singhpriya2861990@gmail.com \\ (iD) https://orcid.org/0000-0003-0110-4242
}

Surya Pratap Singh

Sanjay Gandhi Post graduate Institute of

Medical Science, Lucknow, UP, India

(iD) https://orcid.org/0000-0002-3544-2023

DOI: https://doi.org/10.20883/medical.e555
Keywords: COVID-19, Splenic infarcts, Acute Aortic thrombus

Published: 2021-12-29

\begin{abstract}
How to Cite: Singh P, Pratap Singh S. Acute Aortic Thrombus with Splenic Infarction in a Patient with COVID-19 Infection. Journal of Medical Science. 2021 Dec 29;90(4):e555. doi:10.20883/medical.e555
\end{abstract}

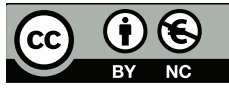

C) 2021 by the author(s). This is an open access article distributed under the terms and conditions of the Creative Commons Attribution (CC BY-NC) licencse. Published by Poznan University of Medical Sciences

\section{ABSTRACT}

Acute Aortic thrombus with splenic infarction is a rare complication of COVID-19. This manuscript highlights the importance of early identification of this complication with abdominal imaging and early initiation of anticoagulation despite moderate severity of the disease.

\section{Description}

A 40-year male with COVID-19 infection presented to the emergency department of a dedicated COVID-19 hospital with complaints of dyspnoea and fever of 2 days duration. His nasopharyngeal and oropharyngeal swabs were positive for COVID-19, and he had been under home isolation for 5 days. He had already received azithromycin $500 \mathrm{mg}$ OD and Ivermectin $12 \mathrm{mg}$ OD for 3 days, doxycycline $100 \mathrm{mg} \mathrm{BD}$ for the next 2 days, and analgesics for 5 days. On admission, his oxygen saturation was $93 \%$ on room air, heart rate $96 /$ min, blood pressure $136 / 86 \mathrm{~mm} \mathrm{Hg}$, the temperature of $39.1^{\circ} \mathrm{C}$, a respiratory rate of $21-25$. He did not have any comorbidities. High-resolution computed tomography (CT) chest (Figure 1) demonstrated multiple peripheral areas of consolidation and ground-glass opacities signifi- cant of viral pneumonitis. His CT severity score (CTSS) was $9 / 25$. Laboratory test revealed mildly increased CRP (0.8 mg/dL), ferritin (668 $\mathrm{ng} / \mathrm{dL})$, LDH (378 U/L), and normal D-dimer. The patient was kept on supplemental oxygen and treated with methylprednisolone $20 \mathrm{mg}$ IV BD and ceftriaxone $1 \mathrm{gm}$ OD. On day 4 of his admission, he developed severe acute abdominal pain in the left hypochondrium. On examination, his abdomen was soft, non-tender, and he presented no organomegaly on palpation. An emergency abdominal contrast-enhanced CT (Figure 2) was performed which revealed a thrombus in the upper abdominal aorta and splenic artery with the associated partial splenic infarction. There was no sign of aortic atherosclerosis. Electrocardiogram and Echocardiographic examinations were normal. His coagulation profile revealed elevated D-dimer $(1800 \mathrm{ng} / \mathrm{ml})$ with mildly decreased plate- 


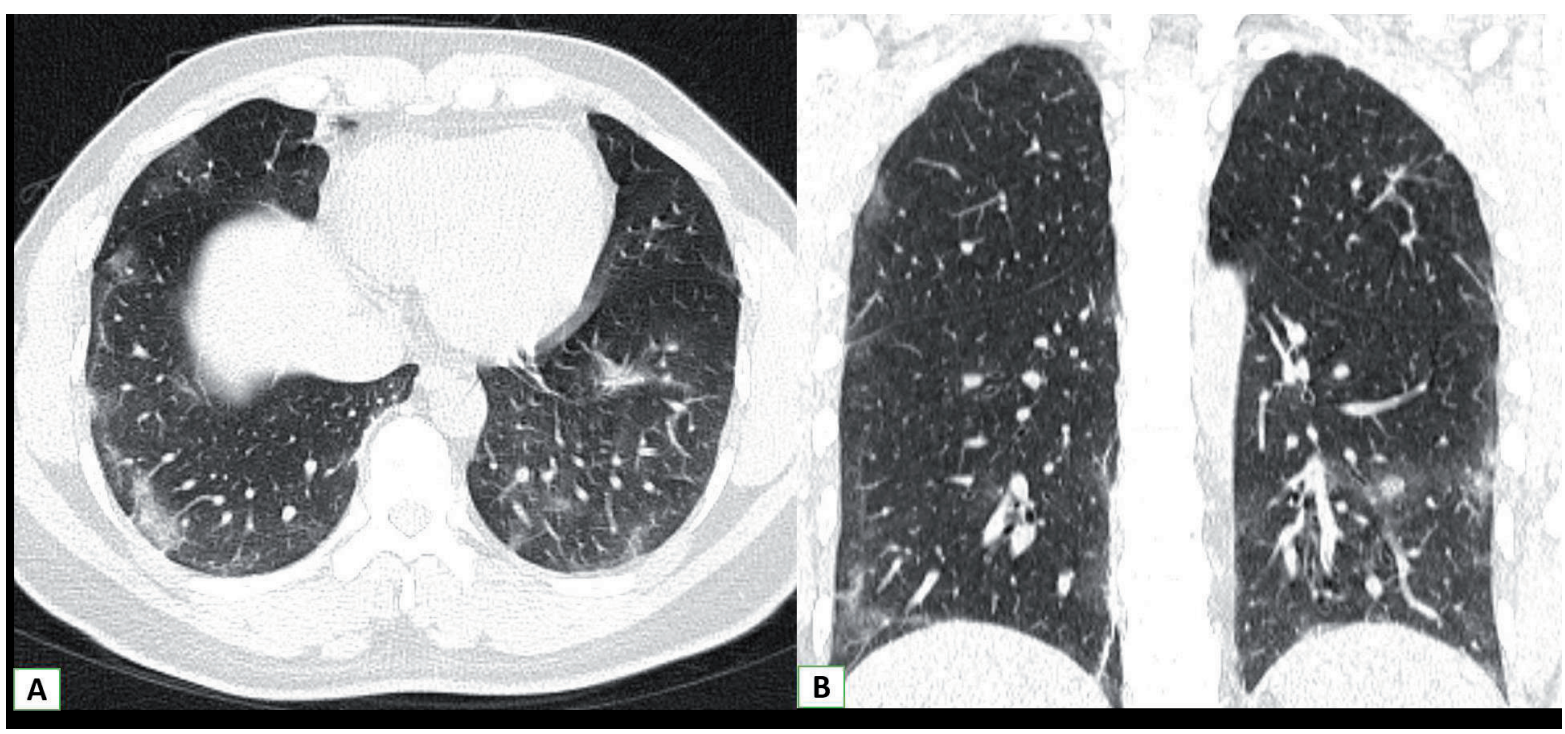

Figure 1. High resolution computed tomography of the thorax, axial (A) and coronal (B) images present multiple patchy areas of ground-glass opacities and consolidation in bilateral lungs predominately in the subpleural location. Findings are consistent with COVID-19 pneumonia
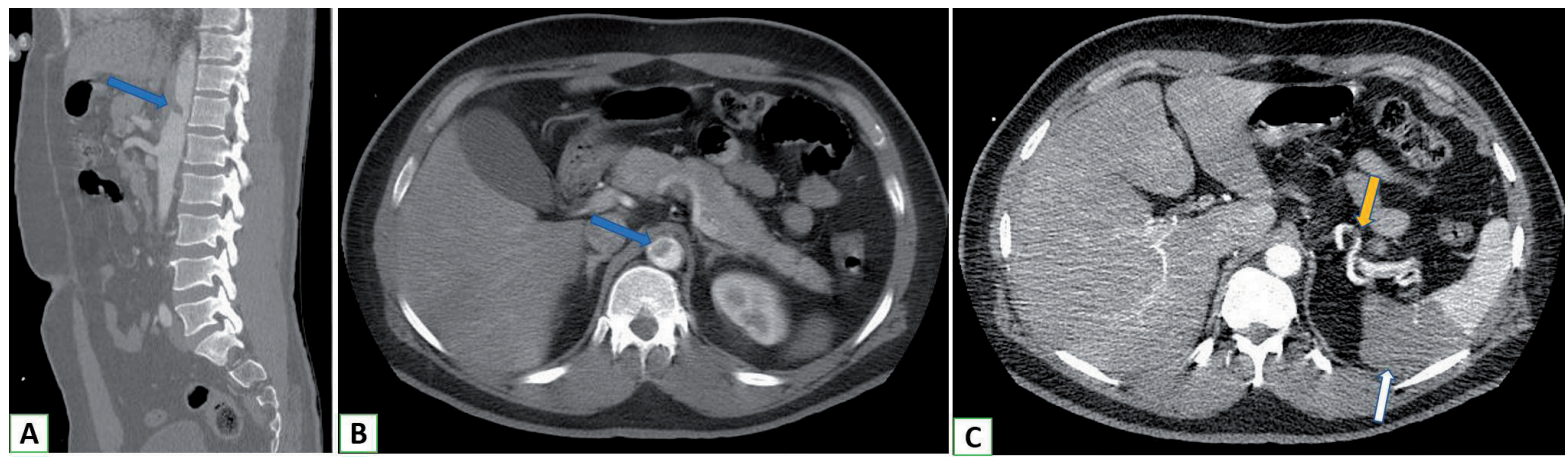

Figure 2. Contrast-enhanced computed tomography (CECT) of the abdomen; sagittal (A) and axial (B and C) images show a small non-enhancing filling defect in the abdominal aorta (blue arrows) and splenic artery (yellow arrow) significant of thrombus. Associated partial splenic infarction is presented in picture $\mathrm{C}$ (white arrow)

let count $\left(100 \times 10^{3} / \mu \mathrm{l}\right)$. As the aortic thrombosis was small, partial and non-obstructive on $\mathrm{CT}$, the patient was scheduled for initial therapeutic anticoagulation, followed by catheter guided thrombolysis if the thrombus persisted. The patient was treated with tramadol and heparin bolus ( 80 units $/ \mathrm{kg}$ ), which were followed by a continuous infusion of heparin (18 units/kg/hr) for 24 hours. The patient responded positively, and a complete resolution of abdominal symptoms and thrombosis was observed. Subsequently, Low Molecular Weight Heparin (LMWH) $60 \mathrm{mg}$ twice daily was administered for 5 days (the patient's weight was $64 \mathrm{~kg}$ and serum creatinine amounted to $1.6 \mathrm{mg} /$ $\mathrm{dl}$ ). Doses of steroids were gradually reduced and discontinued, whereas the anticoagulant medication was replaced with oral rivaroxaban (10 $\mathrm{mg}) \mathrm{OD}$ at discharge. At discharge $\left(11^{\text {th }}\right.$ day of his admission), the patient was clinically asymptomatic, his oxygen saturation returned to $96 \%$ at room air and he tested negative in the real-time PCR assay.

Thrombotic events are currently recognized as one of the major complications of COVID-19 infection. In fact, a hypercoagulable state in COVID-19 patients predisposes them to both arterial and venous thrombosis [1]. The proposed mechanism for thrombosis includes endothelial damage, pro-inflammatory cytokine release, systemic inflammatory response, hypoxia, and 
disseminated intravascular coagulation [1]. Furthermore, the presence of thrombotic complications has also been positively correlated with the severity of the disease [2]. Additionally, solid-organ infarction develops secondary to thrombosis of the vessel supplying the organ; however, in most cases, no thrombus is visible possibly due to the presence of multiple microthrombi [3]. Splenic infarctions are usually treated conservatively, unless some complications or exacerbations of symptoms occur. Thus, acute aortic thrombus can be treated either with therapeutic anticoagulation, catheter guided thrombolysis, or surgical thrombectomy depending on the clinical symptoms, as well as on the extent and size of the thrombus [1]. Thrombotic events may constitute the presenting symptoms of COVID-19 infection, or they can develop subsequently in the course of the disease. This, in turn, highlights the significance of abdominal imaging in patients reporting abdominal symptoms [3]. Moreover, in cases presenting solely with abdominal symptoms, imaging examinations of the abdomen allow for the identification of COVID-19 lesions in lung bases, hence providing a clue with regard to the diagnosis [4]. Our case further validates the employment of anticoagulant prevention in all patients with moderate to severe course of the disease, despite the absence of comorbidities, and initial normal D-dimer as well as coagulation profile.

\section{Learning Points}

1. COVID-19 infection is a prothrombotic state with a high risk of both arterial and venous thrombosis.

2. COVID-19 patients presenting with abdominal symptoms should undergo abdominal imaging examinations aimed at ruling out thrombotic complications.

3. Splenic infarction is a rare disorder which can present with left-sided abdominal pain and can be secondary to a hypercoagulable state in COVID-19 patients.

\section{Acknowledgements}

\section{Contributors}

All authors contributed equally to this manuscript. Both were involved in case management, collection of images and writing.

\section{Conflict of interest statement}

The authors declare no conflict of interest.

\section{Funding sources}

There are no sources of funding to declare.

\section{References}

1. Bikdeli B, Madhavan MV, Jimenez D, Chuich T, Dreyfus I, Driggin E, Nigoghossian C, Ageno W, Madjid M, Guo Y, Tang LV, Hu Y, Giri J, Cushman M, Quéré I, Dimakakos EP, Gibson CM, Lippi G, Favaloro EJ, Fareed J, Caprini JA, Tafur AJ, Burton JR, Francese DP, Wang EY, Falanga A, McLintock C, Hunt BJ, Spyropoulos AC, Barnes GD, Eikelboom JW, Weinberg I, Schulman S, Carrier M, Piazza G, Beckman JA, Steg PG, Stone GW, Rosenkranz S, Goldhaber SZ, Parikh SA, Monreal M, Krumholz HM, Konstantinides SV, Weitz JI, Lip GYH; Global COVID-19 Thrombosis Collaborative Group, Endorsed by the ISTH, NATF, ESVM, and the IUA, Supported by the ESC Working Group on Pulmonary Circulation and Right Ventricular Function. COVID-19 and Thrombotic or Thromboembolic Disease: Implications for Prevention, Antithrombotic Therapy, and Follow-Up: JACC State-of-the-Art Review. J Am Coll Cardiol. 2020 Jun 16;75(23):29502973. doi: 10.1016/j.jacc.2020.04.031. Epub 2020 Apr 17. PMID: 32311448; PMCID: PMC7164881.

2. Malas MB, Naazie IN, Elsayed N, Mathlouthi A, Marmor R, Clary B. Thromboembolism risk of COVID-19 is high and associated with a higher risk of mortality: A systematic review and meta-analysis. EClinicalMedicine. 2020 Dec;29:100639. doi: 10.1016/j. eclinm.2020.100639. Epub 2020 Nov 20. PMID: 33251499; PMCID: PMC7679115.

3. Dane B, Smereka P, Wain R, Kim D, S Katz D. Hypercoagulability in Patients With Coronavirus Disease (COVID-19): Identification of Arterial and Venous Thromboembolism in the Abdomen, Pelvis, and Lower Extremities. AJR Am J Roentgenol. 2021 Jan;216(1):104-105. doi: 10.2214/AJR.20.23617. Epub 2020 Sep 22. PMID: 32603220.

4. Siegel A, Chang PJ, Jarou ZJ, Paushter DM, Harmath $\mathrm{CB}$, Arevalo JB, Dachman A. Lung Base Findings of Coronavirus Disease (COVID-19) on Abdominal CT in Patients With Predominant Gastrointestinal Symptoms. AJR Am J Roentgenol. 2020 Sep;215(3):607609. doi: 10.2214/AJR.20.23232. Epub 2020 Apr 17. PMID: 32301631. 